\title{
HAZARD IDENTIFICATION DAN RISK ASSESSMENT (HIRA) PADA PENGOPERASIAN FORKLIFT DI PT. BANGUN SARANA BAJA - GRESIK
}

\author{
HAZARD IDENTIFICATION AND RISK ASSESSMENT (HIRA) ON FORKLIFT \\ OPERATION AT PT. BANGUN SARANA STEEL - GRESIK
}

\author{
Fitri Suryanti ${ }^{1}$, Mulyono ${ }^{2}$ \\ Departemen Keselamatan dan Kesehatan Kerja Fakultas Kesehatan Masyarakat \\ Universitas Airlangga \\ fitsuryanti@gmail.com
}

\begin{abstract}
Today's modern society tend to need the role of the tools that is able to shorten the time of work. No wonder that advanced technology into a basic work tool operating today. One of them is the adopted transport aircraft, which is a tool that serves as a mover, transport goods or lifter or people vertically or horizontally and with a certain distance. Forklift AIDS belongs as a transport lift aircraft. PT. Bangun Sarana Baja - Gresik is a company engaged in the field of construction and steel fabrication utilizing a forklift as material handling equipment. This research is descriptive research using the architecture of cross sectional. Data collection is done by observation and interviews to 15 forklifts as well as HSE team operator PT. Bangun Sarana Baja - Gresik in order to evaluate the hazard identification and risk assessment (HIRA) on the operation of forklifts. To get the level of risk in the risk assessment done calculations the value of severity and probability. Research results show that the hazard identification and risk assessment in forklift operation in PT. Bangun Sarana Baja - Gresikfound 31 potential dangers that are categorized as potential dangers to the level of risk of the extreme categories by as much as 14, potential hazard with high risk level categories as 6, as well as the potential danger with the level of risk categories are a total of 11. Activities of the hazard identification and risk assessment (HIRA) done by expanding the objects of observation on the stages of the activity of operation of forklifts and the working environment will help control the hazards work environment, so as to minimize work accidents in the Wake of PT. Bangun Sarana Baja - Gresik.
\end{abstract} Keywords: individual characteristics, workers, metal plating, dermatitis 


\section{ABSTRAK}

Masyarakat modern saat ini cenderung membutuhkan peran alat bantu yang mampu mempersingkat waktu pekerjaan. Tak heran bila teknologi mutakhir menjadi basic pengoperasian alat bantu kerja dewasa ini. Salah satunya adalah pesawat angkat angkut, yakni suatu alat bantu yang berfungsi sebagai pemindah, pengangkat atau pengangkut barang maupun orang secara vertikal dan atau horizontal dengan jarak tertentu. Alat bantu forklift tergolong sebagai pesawat angkat angkut. PT. Bangun Sarana Baja - Gresik merupakan perusahaan yang bergerak dalam bidang fabrikasi dan konstruksi baja memanfaatkan forklift sebagai material handling equipment. Penelitian ini merupakan penelitian deskriptif dengan menggunakan rancang bangun cross sectional. Pengumpulan data dilakukan dengan observasi dan wawancara kepada 15 operator forklift serta tim HSE PT. Bangun Sarana Baja - Gresik guna mengevaluasi hazard identification dan risk assessment (HIRA) pada pengoperasian forklift. Untuk mendapatkan tingkat risiko pada risk assessment maka dilakukan perhitungan nilai severity dan probability. Hasil penelitian menunjukan bahwa hazard identification dan risk assessment pada pengoperasian forklift di PT. Bangun Sarana Baja - Gresik didapati 31 potensi bahaya yang dikategorikan sebagai potensi bahaya dengan tingkat risiko kategori ekstrim sebanyak 14 , potensi bahaya dengan tingkat risiko kategori tinggi sebanyak 6, serta potensi bahaya dengan tingkat risiko kategori sedang sebanyak 11. Kegiatan hazard identification dan risk assessment (HIRA) yang dilakukan dengan memperluas objek pengamatan pada tahapan aktivitas pengoperasian forklift dan lingkungan kerja akan membantu mengendalikan bahaya lingkungan kerja, sehingga dapat meminimalisir kecelakaan kerja di PT. Bangun Sarana Baja - Gresik.

\section{Kata Kunci : hazard identification, risk assessment, forklift}

\section{PENDAHULUAN}

Manusia dalam kesehariannya dipenuhi dengan beragam aktivitas yang mana berperan pada peningkatan kualitas hidupnya. Untuk membantu penyelesaian aktifitas tersebut, tak jarang bila peran dari alat bantu pekerjaan dimanfaatkan. Tentunya alat bantu pekerjaan didesain khusus guna menunjang jenis pekerjaan tersebut agar terselesaikan secara efektif dan efisien. Dari waktu ke waktu, ragam jenis aktifitas manusia semakin bervariasi karena tuntutan modernisasi. Oleh karenanya, alat bantu pekerjaan pun juga semakin banyak jenis dan peruntukannya. Masyarakat modern saat ini cenderung membutuhkan peran alat bantu yang mampu mempersingkat waktu pekerjaan. Tak heran bila teknologi mutakhir dimanfaatkan guna menciptakan alat bantu kerja yang dibutuhkan. Salah satunya adalah pesawat angkat angkut.

Pesawat angkat dan angkut adalah suatu pesawat atau alat yang digunakan untuk memindahkan, mengangkat muatan baik bahan atau barang maupun orang secara vertical dan atau horizontal dengan jarak yang ditentukan. Penggunaannya untuk memindahkan sebuah barang dengan jarak, besar dan berat tertentu yang sulit untuk dilakukan ataupun tidak mungkin dilakukan dengan tenaga manusia. Prinsip kerjanya berasal dari konsep pesawat sederhana yang disempurnakan dengan menggunakan teknologi masa kini. Pada umumnya, pesawat angkat angkut mempunyai dimensi yang cukup besar pada setiap unitnya. Hal ini selaras dengan kebutuhan untuk menyelesaikan tugas berat. Oleh karenya muncul istilah heavy equipment dalam penamaannya. Perusahaan barang maupun jasa sering kali membutuhkan pesawat angkut dalam proses produksinya. Adapun peraturan perundangundangan yang mengatur yakni Peraturan Menteri Tenaga Kerja Republik Indonesia No 05 Tahun 1985 tentang Pesawat Angkat Angkut.

Jenis pesawat angkat angkut pun beragam sesuai dengan kegunaannya. Satu di antaranya adalah forklift. Dalam bidang material handling, forklift mempunyai peran penting. Setiap perusahaan pada proses produksinya selalu menerapkan material handling yang baik, guna memperlancar serta menjaga setiap material 
atau bahan yang digunakan maupun yang dihasilkan. Sehingga bilamana menerangkan material handling, terdapat berbagai proses yang dimulai dari penanganan hingga pengawasan material. Dilihat dari fungsinya, forklift tergolong sebagai salah satu material handling equipment yang sering dijumpai pada area pergudangan dalam suatu perusahaan. Forklift mempunyai tugas utama memindahkan barang dari satu tempat ke tempat lain. Dengan demikian, pekerja yang bertugas memindahkan barang sangat terbantu dengan adanya alat bantu kerja forklift ini, karena tidak mengeluarkan tenaga berlebih dan mempersingkat waktu pengerjaan tugas yang diembannya.

Di sisi lain, forklift adalah salah satu jenis pesawat angkat angkut yang merupakan peralatan teknik dengan risiko bahaya tinggi yang dapat menyebabkan terjadinya kecelakaan kerja bilamana tidak ditangani secara baik dan benar. Forklift merupakan salah satu jenis pesawat angkut di atas landasan dan di atas permukaan.

Pada ruang lingkup Keselamatan dan Kesehatan Kerja (K3) yang selalu mengutamakan dan melindungi segi keselamatan dan kesehatan para pekerja guna meningkatkan produktivitas kerja, dimana dioperasikan pesawat angkat angkut, salah satunya forklift baik di tempat kerja industri berpeluang menimbulkan kecelakaan kerja karena beban lebih, konstruksi tidak layak pakai dan penyebab lainnya yang dapat menimbulkan kerugian korban jiwa dan atau rusaknya material sebagai aset perusahaan dan orang lain di tempat kerja.

Identifikasi bahaya merupakan suatu proses yang dapat dilakukan untuk mengenali seluruh situasi atau kejadian yang berpotensi sebagai penyebab kecelakaan dan penyakit akibat kerja yang mungkin timbul di tempat kerja (Tarwaka, 2008).

Kegiatan identifikasi bahaya dan penilaian risiko di tempat kerja mempunyai tujuan meminimalkan kerugian akibat kecelakaan dan sakit, meningkatkan kesempatan atau peluang untuk meningkatkan produksi melalui suasana kerja yang aman, sehat dan nyaman, memotong mata rantai kejadian kerugian akibat kegagalan produksi yang disebabkan kecelakaan dan sakit, serta pencegahan kerugian akibat kecelakaan dan penyakit akibat kerja (Ramli, 2010).

Setiap organisasi harus menetapkan prosedur mengenai identifikasi bahaya. Kegiatan identifikasi bahaya merupakan tahap pertama dalam manajemen risiko untuk mengetahui masalah $\mathrm{K} 3$ yang ada dalam proses kerja di perusahaan. Identifikasi bahaya sangat penting untuk menentukan bentuk program K3 dan implementasi pengendalian yang akan dilakukan perusahaan (OHSAS 18001:2007).

Risk assessment adalah proses evaluasi risiko yang diakibatkan adanya bahaya, dengan memperhatikan kecukupan pengendalian yang dimiliki, dan menentukan apakah risikonya dapat diterima atau tidak (OHSAS 18001: 2007).

PT. Bangun Sarana Baja - Gresik merupakan sebuah perusaahan yang bergerak dalam bidang fabrikasi dan konstruksi baja yang berlokasi di Jalan Mayjend Sungkono XII/08, Gresik. Proses pembuatan baja yang dimulai dari tahap marking, cutting, drilling atau punching, assembling, welding, finishing, painting, hingga packing dilakukan pada satu lokasi tersebut. Terdapat banyak area kerja yang diberi penamaan gudang atau workshop di lokasi tersebut. Sehingga dalam aktivitas produksi sehari-hari PT. Bangun Sarana Baja - Gresik menggunakan forklift untuk menjalankan peran pada proses material handling, tentunya sekaligus mempekerjakan beberapa operator forklift yang telah tersertifikasi untuk mengoperasikan setiap unit forklift yang digunakan di area kerja.

Dari gambaran aktivitas produksi tersebut, potensi bahaya atau kecelakaan kerja yang berkaitan dengan pengoperasian forklift, sangat mungkin terjadi. Selama kurun waktu lima tahun ke belakang telah terjadi delapan kejadian nearmiss, dua kejadian di tahun 2011, tiga kejadian di tahun 2012, satu kejadian di tahun 2013, satu kejadian di tahun 2014 dan satu 
kejadian di tahun 2016. Kedelapan kejadian kecelakaan tersebut rata-rata terletak pada kesalahan load handling, travelling dan maneuvering forklift oleh operator. Tak hanya itu saja, di tahun 2014 sempat terjadi accident forklift yang mengakibatkan cidera pada pekerja.

Oleh karena itu, peneliti ingin mengevaluasi kegiatan hazard identification dan risk assessment (HIRA) pada pengoperasian forklift di PT Bangun Sarana Baja - Gresik, guna mengendalikan potensi bahaya yang ada agar tidak terjadi kecelakaan kerja yang tidak diinginkan sewaktu-waktu.

\section{BAHAN DAN METODE PENELITIAN}

Penelitian ini bertujuan untuk mengevaluasi hazard identification dan risk assessment (HIRA) pada pengoperasian forklift di PT. Bangun Sarana Baja - Gresik. Sehingga penelitian ini termasuk dalam kategori penelitian deskriptif yang mempunyai tujuan utama yakni memberi gambaran obyektif terhadap suatu keadaan dengan cara mendeskripsikanya. Ditinjau dari waktu penelitian termasuk dalam penelitian cross sectional dimana variabel obyek penelitian dianalisis dan dikumpulkan pada satu waktu. Sementara, ditinjau dari tempat, penelitian ini termasuk penelitian lapangan.

Obyek penilitian merupakan hazard identification dan risk assessment (HIRA) pada pengoperasian forklift. Populasi penelitian yakni seluruh operator forklift yang berjumlah 15 orang. Penelitian ini berlokasi di PT. Bangun Sarana Baja -
Gresik, tepatnya di Jalan Mayjend Sungkono XII/08, Gresik, Jawa Timur yang dilakukan pada bulan Juni 2016.

Data yang dikumpulkan terdiri dari data primer dan data sekunder. Data primer diperoleh dengan melakukan dua cara, yakni : 1) Observasi atau pengamatan pada lingkungan kerja pengoperasian forklift yakni di area workshop atas dan workshop bawah di PT. Bangun Sarana Baja - Gresik, dan 2) Wawancara dengan pihak-pihak terkait meliputi operator forklift serta manager departemen HSE sekaligus para anggotanya untuk memperoleh data terkait potensi bahaya dan penilaian risiko pada pengoperasian forklift di PT. Bangun Sarana Baja - Gresik. Data sekunder diperoleh dari data perusahaan yang dikelola departemen HSE bagian administrasi, yang meliputi: 1) Profil perusahaan, 2) Kebijakan K3, dan 3) Instruksi Kerja (IK) forklift.

Data yang diperoleh melalui kegiatan observasi dan wawancara selanjutnya akan diolah dengan melakukan identifikasi bahaya (hazard identification) menggunakan lembar Job Safety Analysis (JSA). Kemudian, hasil dari proses identifikasi tersebut dilakukan penilaian risiko (risk assessment) melalui tahap perhitungan dan penentuan tingkat risiko melalui perkalian tingkat keparahan (severity) yang dapat dilihat pada tabel 1 dan tingkat kemungkinan (likelihood) yang dapat dilihat pada tabel 2 sehingga diperoleh tingkat risiko (rank risk) yang dihasilkan dengan menggunakan risk matrix yang dapat dilihat pada tabel 3 .

Tabel 1. Skala severity

\begin{tabular}{|c|c|c|}
\hline Tingkat & Deskripsi & Keterangan \\
\hline 1 & Insignificant & Tidak terjadi cidera, kerugian finansial sedikit \\
\hline 2 & Minor & Cidera ringan, kerugian finansial sedikit \\
\hline 3 & Moderate & $\begin{array}{c}\text { Cidera sedang, perlu penanganan medis, kerugian } \\
\text { finansial besar }\end{array}$ \\
\hline 4 & Major & $\begin{array}{c}\text { Cidera berat }>1 \text { orang, kerugian besar, gangguan } \\
\text { produksi }\end{array}$ \\
\hline 5 & Catastrophic & $\begin{array}{c}\text { Fatal }>1 \text { Orang, kerugian sangan besar dan dampak } \\
\text { sangat luas, terhentinya seluruh kegiatan }\end{array}$ \\
\hline
\end{tabular}

Sumber : AS/NZS 4360 
Tabel 2. Skala likelihood

\begin{tabular}{ccc}
\hline Tingkat & Deskripsi & Keterangan \\
\hline 1 & Rare & Hampir tidak pernah, sangat jarang terjadi \\
2 & Unlikely & Jarang terjadi \\
3 & Posibble & Dapat terjadi sekali-sekali \\
4 & Likely & Sering terjadi \\
5 & Almost Certain & Dapat terjadi setiap saat \\
\hline
\end{tabular}

Sumber : AS/NZS 4360

Tabel 3. Skala risk matrix

\begin{tabular}{cccccc}
\hline Frekuensi & \multicolumn{5}{c}{ Dampak Risiko } \\
\cline { 2 - 6 } Risiko & $\mathbf{1}$ & $\mathbf{2}$ & $\mathbf{3}$ & $\mathbf{4}$ & $\mathbf{5}$ \\
\hline 1 & $\mathrm{H}$ & $\mathrm{H}$ & $\mathrm{E}$ & $\mathrm{E}$ & $\mathrm{E}$ \\
2 & $\mathrm{M}$ & $\mathrm{H}$ & $\mathrm{E}$ & $\mathrm{E}$ & $\mathrm{E}$ \\
3 & $\mathrm{~L}$ & $\mathrm{M}$ & $\mathrm{H}$ & $\mathrm{E}$ & $\mathrm{E}$ \\
4 & $\mathrm{~L}$ & $\mathrm{~L}$ & $\mathrm{M}$ & $\mathrm{H}$ & $\mathrm{E}$ \\
5 & $\mathrm{~L}$ & $\mathrm{~L}$ & $\mathrm{M}$ & $\mathrm{H}$ & $\mathrm{H}$ \\
\hline
\end{tabular}

Sumber : AS/NZS 4360

\section{HASIL PENELITIAN DAN PEMBAHASAN}

Hasil

Selama tahun 2011 hingga 2014 telah terjadi enam kejadian nearmiss, dan satu accident pada pengoperasian forklift PT Bangun Sarana Baja - Gresik. Pada umumnya kejadian tersebut disebabkan ini: karena kesalahan pada fungsi pengoperasian atau aktivitas forklift oleh operator, sehingga berdampak pada kerugian yang harus ditanggung meliputi kerusakan material yang dibawa, forklift sekaligus cidera yang dialami oleh operator forklift maupun pekerja lainnya. Jumlah kejadian tersebut disajikan pada tabel 4 berikut

Tabel 4. Distribusi Kecelakaan Kerja Pada Pengoperasian Forklift PT Bangun Sarana Baja - Gresik

\begin{tabular}{|c|c|c|c|c|c|}
\hline Tahun & $\begin{array}{c}\text { Kecelakaan } \\
\text { Kerja }\end{array}$ & Dampak & Tindakan & Keterangan & $\begin{array}{c}\text { Jumlah } \\
\text { Kejadian }\end{array}$ \\
\hline 2011 & $\begin{array}{l}\text { Kebakaran } \\
\text { kabel }\end{array}$ & $\begin{array}{l}\text { Mesin forklift } \\
\text { rusak }\end{array}$ & $\begin{array}{l}\text { Perbaikan } \\
\text { forklift }\end{array}$ & $\begin{array}{l}\text { Perbaikan mesin } \\
\text { oleh departemen } \\
\text { mekanik }\end{array}$ & 1 \\
\hline \multirow[t]{3}{*}{2012} & $\begin{array}{l}\text { Forklift } \\
\text { terbalik }\end{array}$ & $\begin{array}{l}\text { Operator } \\
\text { mengalami } \\
\text { luka ringan } \\
\text { atau memar }\end{array}$ & $\begin{array}{l}\text { Tindakan } \\
\text { medis oleh } \\
\text { tim HSE }\end{array}$ & $\begin{array}{l}\text { Penanganan } \\
\text { dengan P3K oleh } \\
\text { HSE }\end{array}$ & 1 \\
\hline & & $\begin{array}{l}\text { Kerusakan } \\
\text { material }\end{array}$ & $\begin{array}{l}\text { Perbaikan } \\
\text { material }\end{array}$ & $\begin{array}{l}\text { Perbaikan } \\
\text { material oleh } \\
\text { subkon }\end{array}$ & \\
\hline & $\begin{array}{l}\text { Material } \\
\text { jatuh }\end{array}$ & $\begin{array}{l}\text { Pekerja lain } \\
\text { mengalami } \\
\text { luka ringan } \\
\text { atau memar }\end{array}$ & $\begin{array}{l}\text { Tindakan } \\
\text { medis oleh } \\
\text { tim HSE }\end{array}$ & $\begin{array}{l}\text { Penanganan } \\
\text { dengan P3K oleh } \\
\text { HSE }\end{array}$ & 2 \\
\hline 2013 & $\begin{array}{l}\text { Material } \\
\text { jatuh }\end{array}$ & $\begin{array}{l}\text { Pekerja lain } \\
\text { mengalami } \\
\text { luka ringan } \\
\text { atau memar }\end{array}$ & $\begin{array}{l}\text { Tindakan } \\
\text { medis oleh } \\
\text { tim HSE }\end{array}$ & $\begin{array}{l}\text { Penanganan } \\
\text { dengan P3K oleh } \\
\text { HSE }\end{array}$ & 2 \\
\hline 2014 & $\begin{array}{l}\text { Forklift } \\
\text { terbalik }\end{array}$ & $\begin{array}{l}\text { Operator } \\
\text { mengalami } \\
\text { luka ringan } \\
\text { atau memar }\end{array}$ & $\begin{array}{l}\text { Tindakan } \\
\text { medis oleh } \\
\text { tim HSE }\end{array}$ & $\begin{array}{l}\text { Penanganan } \\
\text { dengan P3K oleh } \\
\text { HSE }\end{array}$ & 1 \\
\hline
\end{tabular}




\begin{tabular}{|l|l|l|l|c|}
\hline & $\begin{array}{l}\text { Kerusakan } \\
\text { material }\end{array}$ & $\begin{array}{l}\text { Perbaikan } \\
\text { material }\end{array}$ & $\begin{array}{l}\text { Perbaikan } \\
\text { material oleh } \\
\text { subkon }\end{array}$ & $\mathbf{7}$ \\
\hline
\end{tabular}

Sumber : Data Sekunder PT. Bangun Sarana Baja - Gresik

Karakteristik operator forklift PT. Bangun Sarana Baja - Gresik ikut menjadi bagian pengamatan, yaitu meliputi usia, jenis kelamin, masa kerja, pendidikan, serta kepemilikan Surat Ijin Operator (SIO). Dari 15 operator forklift, keseluruhannya memiliki kesamaan dari sisi jenis kelamin yakni laki-laki, pendidikan terkahir hingga bangku SMA dan telah mengantongi SIO. Namun, usia dan masa kerja 15 operator forklift tidak sama. Pada tabel 5 dan tabel 6 berisikan informasi tersebut yang disajikan secara lengkap dan detail.

Tabel 5. Distribusi Usia Operator Forklift PT Bangun Sarana Baja - Gresik

\begin{tabular}{|c|c|c|}
\hline Umur (Tahun) & Jumlah & $\%$ \\
\hline $17-25$ & 1 & 6,67 \\
$26-35$ & 5 & 33,33 \\
$36-45$ & 6 & 40 \\
$\geq 46$ & 3 & 20 \\
\hline Jumlah & 15 & 100 \\
\hline
\end{tabular}

Sumber: Wawancara

Tabel 6. Distribusi Masa Kerja Operator Forklift PT Bangun Sarana Baja - Gresik

\begin{tabular}{|c|c|c|}
\hline Masa Kerja (Tahun) & Jumlah & $\%$ \\
\hline $0-5$ & 2 & 13,33 \\
$6-10$ & 4 & 26,67 \\
$11-15$ & 6 & 40 \\
$>15$ & 3 & 20 \\
\hline Jumlah & 15 & 100 \\
\hline
\end{tabular}

Sumber: Wawancara

Identifikasi bahaya dengan memanfaatkan JSA dilakukan pada setiap tahapan aktivitas operasional forklift serta lingkungan kerja pengoperasian forklift. Berdasarkan identifikasi bahaya tersebut, ditemukan sebanyak 31 potensi bahaya.

Temuan sebanyak 31 potensi bahaya yang didapatkan dari proses identifikasi bahaya digunakan sebagai acuan untuk melakukan risk assessment dengan melibatkan penentuan besaran kemungkinan (likelihood) dan keparahan (severity) yang timbul dari potensi bahaya tersebut. Selanjutnya, dua penentuan tersebut dituangkan ke dalam risk matrix guna melihat besaran tingkat risiko yang dihasilkan. Pada risk matrix akan terlihat kategori dari tingkat risiko potensi bahaya yakni extreme, high, middle, dan low.

Hasil risk assessment dari tahapan operasional dan lingkungan kerja forklift di PT. Bangun Sarana Baja - Gresik, didapatkan hasil bahwa sebanyak potensi bahaya dikategorikan sebagai potensi bahaya dengan tingkat risiko kategori ekstrim (extreme) sebanyak 14, potensi bahaya dengan tingkat risiko kategori tinggi (high) sebanyak 6, serta potensi bahaya dengan tingkat risiko kategori sedang (middle) sebanyak 11. Hasil risk assessment dapat dilihat pada tabel 7 dan tabel 8 . 
Tabel 7. Risk Assessment Pada Tahap Operasional Pengoperasian Forklift di PT. Bangun Sarana Baja Gresik

\begin{tabular}{llc}
\hline \multicolumn{1}{c}{ Aktivitas Pekerjaan } & \multicolumn{1}{c}{ Potensi Bahaya } & Rank Risk \\
\hline \multirow{2}{*}{ Menghidupkan forklift } & Kesetrum listrik & $\mathrm{M}$ \\
& Forklift terpelanting maju / mundur & $\mathrm{M}$ \\
\hline \multirow{2}{*}{ Mobilisasi forklift tanpa } & Forklift slip & $\mathrm{M}$ \\
membawa material & Forklift terjungkal & $\mathrm{M}$ \\
& Forklift roboh & $\mathrm{M}$ \\
\hline \multirow{2}{*}{ Mengambil material } & Material roboh & $\mathrm{E}$ \\
& Tertimpa material & $\mathrm{E}$ \\
\hline \multirow{3}{*}{ Mengangkat material } & Kelebihan beban & $\mathrm{M}$ \\
& Terkena swing material & $\mathrm{H}$ \\
& Material roboh & $\mathrm{E}$ \\
& Kegagalan lifting & $\mathrm{H}$ \\
\hline \multirow{5}{*}{ Memindah material } & Material jatuh & $\mathrm{E}$ \\
& Forklift terbalik & $\mathrm{M}$ \\
& Kejatuhan material & $\mathrm{E}$ \\
& Tergores material & $\mathrm{H}$ \\
\hline Meletakkan material & Tersenggol swing material / counter & $\mathrm{M}$ \\
\hline dipindah & yeight & Tergores material \\
& Terjepit material & $\mathrm{H}$ \\
& Tertimpa material & $\mathrm{H}$ \\
& Material roboh & $\mathrm{E}$ \\
\hline
\end{tabular}

Sumber : Observasi dan wawancara

Tabel 8. Risk Assessment Pada Lingkungan Kerja Pengoperasian Forklift di PT. Bangun Sarana Baja Gresik

\begin{tabular}{llc}
\hline \multicolumn{1}{c}{ Lingkungan Kerja } & \multicolumn{1}{c}{ Potensi Bahaya } & Rank Risk \\
\hline \multirow{2}{*}{ Kebisingan } & $\begin{array}{l}\text { Dentuman yang berasal dari alat kerja } \\
\text { lainnya seperti palu dan gerinda yang } \\
\text { menghasilkan kebisingan sebesar 95 } \\
\text { dB (berdasarkan data sekunder). }\end{array}$ & H \\
\hline \multirow{3}{*}{ Banyak tikungan } & $\begin{array}{l}\text { Material jatuh } \\
\text { Forklift terbalik } \\
\text { Kejatuhan material }\end{array}$ & $\mathrm{E}$ \\
\hline \multirow{3}{*}{ Jalan miring } & Material jatuh & $\mathrm{M}$ \\
& Forklift terbalik & $\mathrm{E}$ \\
\hline \multirow{3}{*}{ Jalan sempit } & Kejatuhan material & $\mathrm{M}$ \\
& $\begin{array}{l}\text { Material jatuh } \\
\text { Forklift terbalik } \\
\text { Kejatuhan material }\end{array}$ & $\mathrm{E}$ \\
\hline \multirow{2}{*}{ Debu } & $\begin{array}{l}\text { Debu yang dihasilkan dari proses } \\
\text { produksi dan debu lingkungan. }\end{array}$ & $\mathrm{M}$ \\
\hline
\end{tabular}

Sumber : Observasi dan wawancara

\section{Pembahasan}

Menurut Peraturan Menteri Tenaga Kerja Republik Indonesia No. 3 Tahun 1998 tentang Tata Cara Pelaporan dan Pemeriksaan Kecelakaan Kerja menjelaskan bahwa kecelakaan adalah suatu kejadian yang tidak dikendaki dan tidak diduga semula yang dapat menimbulkan korban manusia dan atau harta benda. Kecelakaan forklift adalah kecelakaan yang terjadi pada saat pengoperasian forklift sehingga menyebabkan kerusakan benda, luka, bahkan kematian (OSHA, 2004).

Menurut Legal Match (2007), terjadinya kecelakaan pada forklift 
dipengaruhi oleh dua faktor yakni faktor manusia dan faktor lingkungan. Faktor manusia meliputi: 1) Usia, semakin muda usia seseorang maka semakin besar potensi terjadinya tindakan yang membahayakan. Hal dikarenakan pribadi usia muda masih dipenuhi dengan sifat emosi, ceroboh dan kurang berpengalaman; 2) Tingkat pendidikan, semakin tinggi tingkat pendidikan maka semakin rendah kejadian kecelakaan yang ditimkbulkan; 3) Masa Kerja, tenaga kerja dengan masa kerja minim cenderung berpeluang besar mengalami kecelakaan kerja; 4) Pelatihan, seorang pekerja akan sulit melaksanakan pekerjaan dengan baik dan cenderung melakukan banyak kesalahan apabila tidak diberi pelatihan terlebih dahulu; 5) Perbuatan yang membahayakan, contohnya bertindak semaunya sendiri dan mengabaikan peraturan berisiko menimbulkan kecelakaan. adapun faktor kedua yakni faktor lingkungan meliputi: 1) Perlindungan yang tidak aman, contohnya pada mesin atau peralatan beregerak yang tidak dilindungi; 2) Kerusakan alat, contohnya peralatan yang kasar atau licin karena kurang pemeliharaan; 3) Konstruksi yang tidak aman dapat membahayakan keselamatan pekerja; 4) Penempatan dan penyusunan yang tidak aman; dan 5) Penerangan yang tidak sempurna, akan menyebakan penglihatan pekerja terganggu sehingga berpotensi besar menimbulkan kecelakaan.

Identifikasi bahaya merupakan landasan dari program pencegahan kecelakaan atau pengendalian risiko. Tanpa mengenal bahaya, maka risiko tidak dapat ditentukan sehingga upaya pencegahan dan pengendalian risiko tidak dapat dijalankan (Ramli, 2010).

Salah satu teknik identifikasi bahaya adalah dengan melakukan Job Safety Analysis (JSA). JSA merupakan cara untuk meneliti bahaya pada tiap langkah kerja, kemudian mencari penyelesaian dari tiap bahaya sehingga bahaya dapat dikendalikan sejak dini (Siswanto, 2009). Identifikasi bahaya pengoperasia forklift di PT Bangun Sarana Baja - Gresik menggunakan JSA didapati sebanyak 31 potensi bahaya.
Pada aktivitas pekerjaan pertama saat pengoperasian forklift adalah aktivitas menghidupkan mesin memiliki dua potensi bahaya, yakni: 1) Tersetrum listrik yang disebabkan oleh instalasi listrik yang rusak, dan 2) Potensi bahaya forklift terpelanting maju atau mundur disebabkan karena tuas maju atau mundur tidak dikembalikan pada kondisi netral sebelum forklift dimatikan.

Aktivitas kedua adalah mobilisasi forklift tanpa membawa material memiliki tiga potensi bahaya, yakni: 1) Forklift slip, 2) Forklift terjungkal, dan 3) Forklift roboh. Hal tersebut dapat disebabkan karena adanya ketidakseimbangan yang terjadi pada saat menjalankan forklift atau operator tidak memperhatikan kondisi jalan dan kecepatan forklift. Menurut Peraturan Menteri Tenaga Kerja No. 5 Tahun 1985 tentang Pesawat Angkat Angkut Pasal 104 bahwa pesawat angkutan di atas landasan dengan motor bakar harus dijalankan dengan aman sesuai dengan kecepatan yang telah ditentukan.

Aktivitas ketiga adalah mengambil material memiliki dua potensi bahaya, yakni: 1) Material roboh, dan 2) Tertimpa material yang dialami oleh pekerja lain yang sedang berada di sekitar forklift. Faktor utama yang menyebabkan potensi bahaya tersebut terjadi adalah material yang diangkat tidak dipastikan dalam keadaan stabil. Susunlah beban barang dengan rapid an seimbang supaya beban tidak dapat tumpah atau jatuh saat diangkat (Wirendeni, 2013).

Aktivitas keempat adalah mengangkat material memiliki empat potensi bahaya, yakni: 1) Kelebihan beban yang disebabkan oleh ketidakpatuhan operator forklift terhadap Instruksi Kerja (IK) forklift dalam proses pengangkatan yang mengharuskan beban pengangkatan tidak melebihi batas kemampuan angkat atau Save Weight Limit (SWL), 2) Terkena swing material dapat terjadi karena operator forklift tidak memastikan kondisi sekitar pengoperasian forklift saat dilakukan pengangkatan jauh dari pekerja lain, 3) Material roboh diakibatkan oleh ketidakstabilan beban atau material yang diangkat, dan 4) Kegagalan lifting 
disebabkan oleh ketidaknormalan kondisi lifting equipment yang meliputi hidrolik, kerangka, dan fork.

Aktivitas kelima adalah
memindahkan material memiliki lima potensi bahaya, yakni: 1) Material jatuh, 2) Forklift terbalik, 3) Kejatuhan material, 4) Tergores material, dan Tersenggol swing material / counter weight. Faktor pemicu potensi bahaya tersebut berasal dari ketidakstabilan material saat sedang dipindahkan, pengereman mendadak, pengangkatan terlalu tinggi, kondisi area swing belum steril dari pekerja dan lain sebagainya. Forklift harus dilengkapi dengan sebuah atap atau pelindung lainnya yang memadai untuk mencegah terjadinya kecelakaan pada operator forklift yang disebabkan oleh benda-benda jatuh (Rochman, 2009).

Aktivitas keenam adalah meletakkan material yang dipindah memiliki empat potensi, yakni: 1) Tergores material terjadi karena ketidakpatuhan pekerja terhadap penggunaan APD yang diwajibkan meliputi helm safety, sepatu safety dan sarung tangan kain, 2) Terjepit material disebabkan oleh proses material handling yang tidak berhati-hati, 3) Tertimpa material diakibatkan oleh penataan material tidak benar, jarak aman dari pengoperasian forklift tidak dikondisikan secara baik, serta ketidakpatuhan operator forklift terhadap Standard Operasional Procedure (SOP), dan 4) Material roboh. Undang-Undang Republik Indonesia No. 1 Tahun 1970 tentang Keselamatan Kerja menyebutkan bahwa tenaga kerja harus memakai alat-alat pelindung diri yang diwajibkan. Beban ditumpuk dengan benar dan seimbang, hatihati terhadap kemungknan runtuhnya tumpukan muatan (Wirendeni, 2013). Menurut Suardi (2005), prosedur merupakan penjelasan aktivitas di perusahaan yang melibatkan banyak orang dari beberapa pihak dan dalam satu prosedur terdapat beberapa instruksi kerja.

Adapun lingkungan kerja tidak luput dari potensi bahaya yang dapat memicu terjadinya kecelakaan kerja yang merugikan sekaligus tidak diinginkan sewaktu-waktu.
Kondisi lingkungan kerja yang terasa bising menghasilkan potensi bahaya berupa dentuman yang berasal dari alat kerja lainnya seperti palu dan gerinda yang menghasilkan kebisingan sebesar $95 \mathrm{~dB}$, sehingga menimbulkan risiko gangguan pendengaran pada pekerja.

Kondisi lingkungan kerja banyak tikungan menghasilkan potensi berupa: 1) Material jatuh, 2) Forklift terbalik, dan 3) Kejatuhan material. Ketiga potensi bahaya tersebut dapat terjadi oleh karena kondisi jalan yang menikung mengakibatkan ketidakstabilan pada forklift apabila operator tidak bisa mengoperasikannya dengan benar. Begitu pula kondisi lingkungan kerja yang terdapat jalan miring dan sempit akibat banyaknya tumpukan material menghasilkan potensi bahaya yang sama dengan kondisi jalan yang menikung, beserta alasan mengapa potensi bahaya tersebut dapat terjadi.

Kondisi lingkungan kerja yang berdebu hasil dari proses produksi dan debu lingkungan mengakibatkan gangguan saluran pernapasan bagi para pekerja, termasuk salah satunya operator forklift.

\section{SIMPULAN DAN SARAN}

\section{Simpulan}

1. Identifikasi bahaya (hazard identification) di PT Bangun Sarana Baja - Gresik dilakukan dengan memanfaatkan JSA dilakukan pada setiap tahapan aktivitas operasional forklift serta lingkungan kerja pengoperasian forklift. Berdasarkan identifikasi bahaya tersebut, ditemukan sebanyak 31 potensi bahaya.

2. Penilaian risiko (risk assessment) dari tahapan operasional dan lingkungan kerja forklift sebagai material handling equipment di PT. Bangun Sarana Baja Gresik, didapatkan hasil bahwa sebanyak 31 potensi bahaya dikategorikan sebagai potensi bahaya dengan tingkat risiko kategori ekstrim (extreme) sebanyak 14, potensi bahaya dengan tingkat risiko kategori tinggi (high) sebanyak 6, serta potensi bahaya dengan tingkat risiko kategori sedang (middle) sebanyak 11. 


\section{Saran}

Proses hazard identification dan risk assessment (HIRA) sebaiknya dilakukan PT Bangun Sarana Baja - Gresik sebaiknya dengan memperluas objek pengamatan yakni tidak hanya pada tahapan aktivitas pengoperasian forklift saja, melainkan lingkungan kerja juga perlu diikutsertakan.

\section{DAFTAR PUSTAKA}

Legal Match. Forklift Accident Lawyers. http://www.legalmatch.com/law_lib rary/article/forklift-accidentlawyers.htm (Sitasi 28 Juli 2016).

Peraturan Menteri Tenaga Kerja Republik Indonesia No. 5 Tahun 1985 tentang Pesawat Angkat Angkut.

Peraturan Menteri Tenaga Kerja Republik Indonesia No. 3 Tahun 1998 tentang

Tata Cara Pelaporan dan Pemeriksaan Kecelakaan Kerja.

Ramli, S. 2010. Sistem Manajemen Keselamatan dan Kesehatan Kerja OHSAS 18001. Jakarta: Dian Rakyat.

Rochman, R. 2009. Penerapan SyaratSyarat Keselamatan Kerja Forklift Sebagai Upaya Pencegahan Kecelakaan Kerja Pada Unit Produksi PT. Surya Rengo Containers. Tugas Akhir. Surabaya: Universitas Airlangga.

Suardi, R. 2005. Sistem Manajemen Keselamatan dan Kesehatan Kerja. Jakarta: Penerbit PPM.

Tarwaka. 2008. Keselamatan dan Kesehatan Kerja "Manajemene dan Implementasi K3 di Tempat Kerja”. Surakarta: Harapan Press.

Undang-Undang Republik Indonesia No. 1 Tahun 1970 tentang Keselamatan Kerja.

Wirendeni. 2013. Panduan Pekerja Kontraktor Geocycle. Jakarta: PT. Holcim Indonesia Tbk. 